\title{
Race, Educational Attainment, and E-Cigarette Use
}

\section{Shervin Assari ${ }^{1}$, Ritesh Mistry ${ }^{2}$, Mohsen Bazargan ${ }^{1,3}$}

${ }^{1}$ Departments of Family Medicine, College of Medicine, Charles R. Drew University of Medicine and Science, Los Angeles, CA 90059, United States, ${ }^{2}$ Department of Health Behavior and Health Education, School of Public Health, University of Michigan, Ann Arbor, MI 48104, United States, ${ }^{3}$ Departments of Family Medicine, University of California, Los Angeles, CA, United States

Address for correspondence: Shervin Assari, Departments of Family Medicine, College of Medicine, Charles R Drew University of Medicine and Science, $118^{\text {th }}$ Street, Los Angeles, CA 90059, United States. E-mail: assari@umich.edu

\section{Abstract}

Background: Although higher educational attainment lowers high-risk behaviors such as substance use, according to the Minorities' Diminished Returns theory, the effect of educational attainment may be smaller for Blacks than Whites. Aims: The aim of the study was to explore the racial differences in the link between educational attainment and electronic cigarettes (e-cigarettes). Methods: We used the Health Information National Trends Survey data. This national survey was conducted in 2017 and included 2277 American adults composed of 1868 White and 409 Black individuals. Educational attainment was the independent variable. E-cigarette use (lifetime) was the dependent variables (DVs). Age and gender were the covariates. Race was the effect of modifier. Results: In the overall sample, a higher level of educational attainment was linked to lower odds of e-cigarette use (Odds ratio $[\mathrm{OR}]=0.76,95 \%$ Confidence Interval $[\mathrm{Cl}]=0.61-0.95$ ). Race showed a significant interaction with educational attainmeWWnt on the outcome ( $O R=1.63,95 \% \mathrm{Cl}=1.04-2.56)$, suggesting a weaker negative association between high educational attainment and e-cigarette use for Blacks than Whites. In race-stratified logistic regression models, high educational attainment was inversely associated with risk of e-cigarette use for Whites but not Blacks. Conclusions: Educational attainment shows a stronger effect on e-cigarette use in White than Black Americans.

Keywords: African-American, Black, Educational attainment, Electronic cigarettes, Ethnicity, Population groups, Race, Socioeconomics, Substance use, Whites

\section{Introduction}

\section{Background}

As explained by the Minorities' Diminished Returns (MDRs) theory, ${ }^{[1-4]}$ high socio-economic status (SES) generates less tangible health outcomes for minority than the majority group. That is, equal socioeconomic resources resultin unequal gainsfavoring the dominant racial group $(s),{ }^{[5-10]}$ with minority populations being at a systemic disadvantage. ${ }^{[11-14]}$ This theory introduces differential effects as a complementary mechanism to differential exposures as an additional mechanism for the persistence of racial health gaps in the US. ${ }^{[1,2]}$ Although high educational attainment is associated with less favorable health behaviors, this theory suggests that the effects of educational attainment on economic and health outcomes are smaller for non-Whites than Whites. ${ }^{[10,15-18]}$
Several social and economic resources have stronger effects for Whites than Blacks. ${ }^{[10,16,18,19]}$ To give a few examples, educational attainment, ${ }^{[10]}$ income, $^{[19]}$ occupation, ${ }^{[14]}$ marital status, ${ }^{[20]}$ residential area quality, ${ }^{[21]}$ coping, ${ }^{[22,23]}$ and number of social contacts ${ }^{[24]}$ all promote health outcomes for White more than Black Americans. It is not fully known, however, whether the MDRs theory also holds for emerging health-related behaviors such as electronic cigarettes (e-cigarettes) use.

Studying socioeconomic determinants of e-cigarette use are particularly important ${ }^{[25-27]}$ because these products are relatively recent health risk products to enter the market and are quickly growing in popularity. ${ }^{[28-31]}$ Although the evidence is still in its infancy, ${ }^{[32]}$ e-cigarettes can be considered a hazard as well as harm-reduction strategy. ${ }^{[3,34]}$

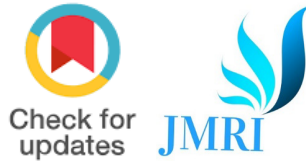

How to cite this article: Assari S, Mistry R, Bazargan M. Race, Educational Attainment, and E-Cigarette Use. J Med Res Innov. 2020;4(1):e000185.

Doi: 10.32892/jmri.185

Publication history: Received: 30-07-2019 Accepted: 13-09-2019

Published: 14-09-2019

Editor: Dr. Varshil Mehta

Copyright: Assari S, Mistry R,Bazargan M. This is an open-access article distributed under the terms of the Creative Commons Attribution License CCBY 4.0., which permits unrestricted use, distribution, and reproduction in any medium, provided the original author and sources are credited.

Funding: Research reported in this publication was supported by the National Cancer Institute of the National Institutes of Health and FDA Center for Tobacco

Products under the award number U54CA229974.

The content is solely the responsibility of the authors and does not necessarily represent the official views of the $\mathrm{NIH}$ or the Food and Drug Administration. Assari and Bazargan are also supported by the NIH under Award \# 54MD008149, R25 MD007610, 2U54MD007598, and U54 TR001627, U54 MD007598, and the CA201415-02.

Conflict of Interest: NIL

MK Medkrux 
When compared to non-smokers, still some risks are associated with electronic cigarettes. ${ }^{[32,35]}$ However, given the lower health risk associated with electronic cigarettes compared to conventional cigarettes, e-cigarettes can be conceptualized as a less risky behavior compared to conventional cigarettes. ${ }^{[3,34]}$ As a result, although overall, public health should aim to reduce prevalence of e-cigarette use; transition from conventional cigarettes to e-cigarettes may be a step forward toward cessation and risk reduction, the transition may also result in continued nicotine addiction. ${ }^{[32]}$ Therefore, e-cigarette use should be still conceptualized as a health risk behavior. ${ }^{[32]}$

Five potential mechanisms may exist behind the diminished returns of educational attainment on health-related outcomes: (1) Labor market discrimination, (2) income and wealth differences, (3) discrimination, (4) growing disadvantage due to initial advantage differences, and (5) high psychosocial tax of minorities. ${ }^{[1,2]}$ Structural racism causes disproportionately higher prevalence of societal barriers in the life of racial and ethnic minorities such as Blacks. ${ }^{[1,2]}$ Although interpersonal discrimination $^{[36]}$ and unequal treatment by the health-care system ${ }^{[1,2]}$ also have unique roles in shaping Minorities Diminished Return, a large proportion of disparities in gains between Blacks compared to Whites is due to the very different life circumstances of social groups. ${ }^{[1,2]}$ Blacks are treated unfairly and unjustly by the society, which places them in a relative disadvantage relative to Whites in their ability to gain benefits from their resources. ${ }^{[1,2]}$ Structural and institutional racism and interpersonal discrimination do increase social, psychological, and biological costs involved in the process of upward social mobility for Blacks. ${ }^{[10,37]}$ As a result, the expected health gains that are expected to follow SES are smaller for Blacks than Whites. ${ }^{[16,38,39]}$ Residential and job segregation, combined with racism across levels and instructions, reduces the health gain that follows upward social mobility for minorities. ${ }^{[10,37]}$

\section{Aim}

To extend the existing research on the relevance of MDRs theory ${ }^{[1,2]}$ for the effect of educational attainment on substance use, ${ }^{[6,8,18,40]}$ this study aimed to compare Blacks and Whites for the effects of educational attainment on e-cigarette in the US. We hypothesized an inverse association between educational attainment and use of e-cigarettes for Whites but not Blacks.

\section{Methods}

\section{Design and setting}

The Health Information National Trends Survey (HINTS) survey is a national cross-sectional study. The HINTS has been conducting the National Cancer Institute (NCI). HINTS study generates a generalizable snapshot of cancer-related information about the general population of American adults (age $\geq 18$ ). The HINTS 5-Cycle 1 data were collected in early 2017. The HINTS 5 was a mail survey. Respondents were provided toll-free telephone numbers. ${ }^{[41-43]}$

\section{Sampling}

In the HINTS 5 Cycle 1, the sampling strategy was composed of a two-stage design. First, a stratified sample of addresses was derived from all available residential addresses. Second, one adult was selected from any selected household. All residential properties in the US were considered as eligible for sampling. The Marketing Systems Group provided the addresses. The sampling frame was divided into two sampling strata based on the density of minorities (high versus low).

\section{Measures}

\section{Demographic characteristics}

Ageand genderwere the demographiccharacteristics in this study. Age (years) was measured as a discrete variable; however, it was treated as a continuous measure. Gender was treated as a dichotomous variable (0 male 1 female).

Race

Race was measured as self-identified race using the US Census definitions for "Black or African American" or "White."

Educational attainment (SES) educational attainment was a five-level continuous variable from less than high school ${ }^{[1]}$ to post-baccalaureate degree. ${ }^{[5]}$ Educational attainment was treated as a continuous measure, with a range from 1 to 5 , with a higher score reflecting a higher SES (educational attainment).

\section{E-cigarette use}

Use of e-cigarettes was measured using the following item: "Have you ever used an e-cigarette, even 1 or 2 times?" Response options were yes/no, and a yes response was defined as ever use. This item is used in major national behavioral surveys in the US. Self- 
reported items that are used to measure substance use/cigarette use have high concurrent, criterion, and divergent validity. ${ }^{[4]}$

\section{Statistical analysis}

\section{Data analysis}

Stata 15 (Stata Corp., College Station, Texas, US) was applied to analyze the data. We adjusted for the sampling weights that were available in the HINTS public use files. Thus, we controlled for strata, clustering, as well as non-response. Jackknife method was used to re-estimate the standard errors (SEs). Svy commands were used for all our analyses to adjust for the multi-stage sampling design.

For univariate statistics, we reported (weighted) mean and proportions and associated standard errors (SE). To run bivariate analyses, independent samples $t$-test and Pearson Chi-square tests were used to compare study variables between Whites and Blacks. For multivariable analysis, we fitted four logistic regression models. In all our logistic regression models, educational attainment was the main independent variable (IV), e-cigarette ever use was the main dependent variable (DV), and gender and age were the covariates. Race/ethnicity was the focal moderator. Overall, we ran four models: In the first step, two logistic regressions (Model 1 and Model 2) were estimated in the overall sample. Model 1 did not include any statistical interaction term; however, Model 2 included the race by educational attainment interaction term. In the next step, we estimated Model 3 and Model 4 that were race-specific models. Model 3 was performed for Whites, and Model 4 was performed for Blacks. Odds ratio (OR) associated $95 \%$ Confidence Intervals $(\mathrm{Cl})$, and $P$ value levels were reported. $P<0.05$ was regarded as statistically significant.

We examined a logistic regression model with interaction and a stratified analysis. This is more than just probing the interaction (categorical by categorical interaction) to test the intersection of race and educational attainment on e-cigarette use. This is to increase the consistency and comparability of the literature on Minorities diminished return (MDRs).

\section{Ethics}

The HINTS 5 study protocol received approval from the Westat's Ethics Review Board. The NIH exempted HINTS from a full ethical review. All our participants signed informed consent.

\section{Results}

\section{Descriptive statistics}

This study entered 2277 adult Americans. From this, 1868 were White and 409 Black. Table 1 shows the descriptive characteristics overall and by race/ethnicity. Black participants had lower educational attainment and income than White Americans. Blacks reported less e-cigarette use than Whites [Table 1].

\section{Multivariable models for e-cigarette use in the pooled sample}

Table 2 presents summary of the results of two logistic regression models with educational attainment as the main independent variable and e-cigarette use as the main DV. Model 1 and Model 2 were estimated in the overall sample, with the difference being Model 2, also including the race and educational attainment interaction term. Based on Model 1, high educational attainment was associated with less e-cigarette use $(O R=0.76$, $95 \% \mathrm{Cl}=0.61-0.95)$, net of covariates. Model 2 revealed a significant interaction between race and educational attainment on e-cigarette use (OR = $1.63,95 \% \mathrm{Cl}=1.04-2.56)$, which suggests that the inverse association between educational attainment and e-cigarette use is significantly larger for White than Black individuals [Table 2].

\section{Multivariable models for e-cigarette use by race}

Table 3 shows the results of two additional binary logistic regression models with educational attainment as the predictor and e-cigarette use as the outcome variable for each race. Model 3 and Model 4 were estimated for Whites and Blacks, respectively. In Model 3, high educational attainment was associated with less e-cigarette use for Whites. Model 4 did not show a link between educational attainment and e-cigarette use for Blacks. For Whites, components like age (OR $=0.95 * * * 0.93-0.96)$, income $(0.87 *, 95 \%$ $\mathrm{Cl}=0.76-0.99)$, and educational attainment (OR = $0.72,95 \% \mathrm{Cl}=0.57-0.91$ ) were significant against the e-cigarette use. None of these effects were significant for Blacks [Table 3].

\section{Discussion}

This study showed an inverse association between educational attainment and e-cigarette use, an association which could only observed for Whites but not Blacks.

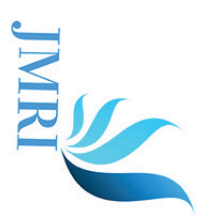


Assari, et al.: Race, educational attainment, and E-cigarette use

Table 1: Descriptive summary of the participants

\begin{tabular}{|c|c|c|c|}
\hline \multirow[t]{2}{*}{ Category } & All $(n=2277)$ & White ( $n=1868)$ & Black $(n=409)$ \\
\hline & Mean (SE) & Mean (SE) & Mean (SE) \\
\hline Age & $48.80(0.34)$ & $50.10(0.46)$ & $47.72(1.22)$ \\
\hline Educational attainment* & $3.12(0.02)$ & $3.17(0.02)$ & $3.08(0.10)$ \\
\hline \multirow[t]{2}{*}{ Income* } & $5.57(0.05)$ & $5.85(0.07)$ & $4.58(0.22)$ \\
\hline & $\%(\mathrm{SE})$ & $\%(\mathrm{SE})$ & $\%(\mathrm{SE})$ \\
\hline \multicolumn{4}{|l|}{ Gender* } \\
\hline Female & $50.63(0.00)$ & $50.84(0.00)$ & $60.86(0.04)$ \\
\hline Male & $49.37(0.00)$ & $49.16(0.00)$ & $39.14(0.04)$ \\
\hline \multicolumn{4}{|l|}{ Educational attainment* } \\
\hline Some high school & $8.37(0.01)$ & $5.54(0.01)$ & $13.69(0.03)$ \\
\hline Graduated from high school & $22.67(0.01)$ & $20.16(0.01)$ & $24.01(0.03)$ \\
\hline Some college degree & $32.98(0.01)$ & $41.03(0.01)$ & $19.36(0.03)$ \\
\hline Bachelor's degree & $22.38(0.01)$ & $20.37(0.01)$ & $26.04(0.04)$ \\
\hline Post-baccalaureate degree & $13.60(0.01)$ & $12.91(0.01)$ & $16.91(0.04)$ \\
\hline \multicolumn{4}{|l|}{ Ever e-cigarette use* } \\
\hline No & $83.16(0.01)$ & $79.18(0.02)$ & $91.64(0.02)$ \\
\hline Yes & $16.84(0.01)$ & $20.82(0.02)$ & $8.36(0.02)$ \\
\hline
\end{tabular}

All numbers of weighted. SE: Standard error. ${ }^{*} P<0.05$ for two-sided comparison of Black and White Americans

Table 2: Two binary logistic regression models $(n=2277)$

\begin{tabular}{|c|c|c|c|c|}
\hline \multirow[t]{2}{*}{ Category } & OR & $95 \% \mathrm{Cl}$ & OR & $95 \% \mathrm{Cl}$ \\
\hline & \multicolumn{2}{|c|}{ Model 1} & \multicolumn{2}{|c|}{ Model 2} \\
\hline \multicolumn{5}{|l|}{ Race } \\
\hline Blacks & $0.22 * * *$ & $0.10-0.49$ & $0.05^{* * *}$ & $0.01-0.29$ \\
\hline Whites & 1 & & & \\
\hline \multicolumn{5}{|l|}{ Gender } \\
\hline Male & 0.92 & $0.57-1.50$ & 0.92 & $0.56-1.50$ \\
\hline Female & 1 & & & \\
\hline Age & $0.95^{* * *}$ & $0.94-0.97$ & $0.95 * * *$ & $0.93-0.96$ \\
\hline Income (1-5) & $0.87 *$ & $0.77-0.99$ & $0.87 *$ & $0.77-0.99$ \\
\hline Educational attainment (1-5) & $0.76^{*}$ & $0.61-0.95$ & $0.73 * *$ & $0.58-0.91$ \\
\hline Race×Educational attainment (1-5) & & & $1.63^{*}$ & $1.04-2.56$ \\
\hline Intercept & $14.24 * * *$ & $4.22-48.00$ & $17.36^{* * *}$ & $5.11-58.94$ \\
\hline
\end{tabular}

${ }^{\#} \mathrm{P}<0.1,{ }^{*} P<0.5,{ }^{* *} P<0.01,{ }^{* * *} P<0.001$. OR: Odds ratio; $\mathrm{Cl}$ : Confidence interval

\section{Findings in the context of other research}

Our finding that educational attainment and income are protective against e-cigarette use is in line with previous research, ${ }^{[1,2]}$ including studies showing that SES indicators protect against smoking cigarettes ${ }^{[8,18]}$ and drinking alcohol. ${ }^{[6,40]}$ High educational attainment lowers prevalence, severity, duration, and consequences of smoking conventional and e-cigarettes. ${ }^{[31]}$ Smoking conventional and e-cigarettes are most common among individuals with the lowest levels of educational attainment and income. ${ }^{[27-31,45]}$ The major contribution of this study, we believe, is not on the main effects of education and income on e-cigarette use but supportive evidence of 
Assari, et al.: Race, educational attainment, and E-cigarette use

Table 3: Two binary logistic regressions by race

\begin{tabular}{|c|c|c|c|c|}
\hline \multirow[t]{3}{*}{ Category } & \multicolumn{2}{|c|}{ Whites ( $n=1868$ ) } & \multicolumn{2}{|c|}{ Blacks ( $n=409)$} \\
\hline & OR & $95 \% \mathrm{Cl}$ & OR & $95 \% \mathrm{Cl}$ \\
\hline & \multicolumn{2}{|c|}{ Model 3} & \multicolumn{2}{|c|}{ Model 4} \\
\hline \multicolumn{5}{|l|}{ Gender } \\
\hline Male & 0.94 & $0.55-1.61$ & 0.78 & $0.18-3.36$ \\
\hline Age & $0.95 * * *$ & $0.93-0.96$ & 0.99 & $0.96-1.02$ \\
\hline Income (1-5) & $0.87^{*}$ & $0.76-0.99$ & 0.85 & $0.56-1.27$ \\
\hline Educational attainment (1-5) & $0.72^{* *}$ & $0.57-0.91$ & 1.19 & $0.67-2.08$ \\
\hline Intercept & $20.20 * * *$ & $5.65-72.21$ & 0.17 & $0.03-1.06$ \\
\hline
\end{tabular}

\#P<0.1, ${ }^{*} P<0.5,{ }^{*} P<<0.01,{ }^{* * *} P<0.001$. OR: Odds ratio; $\mathrm{Cl}$ : Confidence interval

the MDRs theory for e-cigarette use which is an emerging behavioral risk factor in the US and worldwide. Although a few recent studies have shown similar results on smoking cigarettes ${ }^{[8,18]}$ and drinking alcohol, ${ }^{[6,40]}$ no previous studies had shown this pattern for e-cigarette use.

The larger protection of high educational attainment on the mortality risk for White than Black Americans is shown repeatedly. ${ }^{[1,2]}$ The racial differences in the link between educational attainment and e-cigarette use is in line with previous studies that have revealed larger effects of a SES on health outcomes in Whites than Blacks. Smaller effects of SES indicators on anxiety, ${ }^{[20]}$ depression, ${ }^{[12]}$ obesity, ${ }^{[46,47]}$ chronic diseases, ${ }^{[39]}$ and self-rated health, ${ }^{[48,49]}$ and psychological wellbeing ${ }^{[50]}$ are shown for Blacks compared to Whites. MDRs are shown for almost any health and behavioral outcomes ${ }^{[2,9]}$ and have shown for Blacks, ${ }^{[5,20,46,51]}$ gays, ${ }^{[15]}$ and Hispanics. ${ }^{[8,9,11]}$ This suggests that at least some of the mechanisms of MDRs are shared and operate independent of a specific behavior, health outcome, and even specific population. ${ }^{[2,9]}$ Some of these non-specific mechanisms include segregation, social and political power, discrimination, and racism..$^{[2,9]}$

There are also proposed mechanisms that may be involved in substance use and tobacco use. One potential explanation is residential segregation that impacts the density of retails and quality of education in communities of color in the U.S. Another mechanism may be the lower general health literacy of highly educated Black people. Another mechanism may be lower tobacco harm knowledge in highly educated Blacks than Whites. Finally, tobacco industry marketing strategies, that can be predatory at times, may specifically target people of color and low SES individuals in specific areas. Such exposures may increase the vulnerability of high educated Blacks to e-cigarette and other tobacco products.

We deliberately focused in this paper on educational attainment rather than income, wealth, or other SES indicators. This is because research has shown that lower-income and labor market discrimination may be the mechanisms by which educational attainment is associated with less health for Blacks than Whites. ${ }^{[48,50,52]}$ In a study, for example, income mediated MDRs of educational attainment, ${ }^{[48]}$ and other studies, educational attainment generated less income for Blacks than Whites. ${ }^{[52]}$ This is because MDRs are more prominent for more distal processes that many social barriers and processes can interfere with. Stronger MDRs of education than more proximal SES indicators ${ }^{[53]}$ are shown for youth, ${ }^{[47,54,55]}$ adults, ${ }^{[56]}$ and even older adults. ${ }^{[40]}$

The two main competing and complementary conceptual models for health disparities are "race and SES" versus "race or SES."[57-60] These are also relevant to the differential exposures and differential effects. Some of the health disparities literature has reduced racial and ethnic disparities to SES inequalities, however, that approach is oversimplistic and does not allow non-linear effects of SES based on group membership. ${ }^{[2,9]}$ MDRs allow the effects of SES to vary by race/ethnicity, so it considered differential exposure and effects, simultaneously. ${ }^{[2,9]}$

\section{Implications of the findings}

The results have implications for policy, research, and practice. Policies, programs that wish to provide solutions to inequalities should go beyond equalizing racial access to SES resources and identify strategies that help minority populations such as

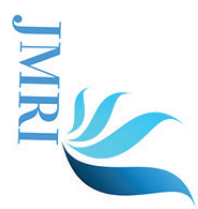


Blacks benefit more tangible economic and health gains from resources that are available to them or they possess. It is easier said than done, but we need to reduce racism and discrimination across all levels of SES and all institutions, including the education system, labor market, and correctional setting. In the absence of such changes, merely reducing the racial gap in SES will never be enough for closing the racial gap in health outcomes.

Tobacco and nicotine use prevention programs that target minority communities should apply a higher dosage of the programs and booster strategies to participants as they benefit less from their SES resources than White counterparts. Blacks need similar programs, regardless of their SES, meaning that high SES Blacks still need more investment to prevent use than high SES Whites..$^{[8,18]}$ The results suggest that programs should enroll Blacks at all SES levels, however, for Whites, need is a function of SES, and there is more need for services for low than high SES Whites. The results may also be relevant to tobacco control community, including health professionals, policy-makers, and community prevention when addressing racial/ ethnic disparities in the harms associated with tobacco and nicotine use. Closing the racial/ethnic health is unlikely unless the interactive effects of race and SES are addressed. Simply reducing the racial gap in SES will not solve the problem.

This study also suggests directions for future research. Diminished returns and differential effects should be regarded as complementary mechanisms in addition to differential exposures, as mechanisms for health disparities. We should seek for the best policies and programs that would reduce the $\mathrm{MDRs}^{[61,62]}$ of educational attainment and other SES indicators. There is also a need to compare the efficacy of universal versus population-specific strategies to prevent substances such as e-cigarette. Future research should investigate to what degree racial differences in the health gains attributable to educational attainment on smoking are due to racism and what proportion is due to other factors such as availability, price, and marketing may also have some role.

The pattern observed here was similar to other studies in which race modifies the economic, behavioral, and health correlates of educational attainment, and e-cigarette use does not seem to be an exception. In the United States, educational attainment consistently generates greater economic and health benefits for Whites than Blacks.

\section{Limitations}

Here, we discuss some of the study limitations. First of all, due to the cross-sectional design of the study, we cannot conclude any causal effects. Longitudinal studies with multiple observations are needed to conclude a causal link between change in SES on substance use, e-cigarette use, and use of other electronic nicotine delivery systems. Thus, there is a need to replicate these findings using upward and downward social mobility over the life course. Second, we used a single item to measures lifetime e-cigarette use. This approach is widely accepted, ${ }^{[44]}$ but more nuanced information using multi-item measures of e-cigarette use, including amount and frequency of use and age of onset need to be studied. Unfortunately, HINTS data did not ask participants additional questions about the frequency of e-cigarette use. Third, underlying mechanisms that explain racial/ethnic differences were not studied. Racial/ethnic differences in employment, family structure, and wealth may be some explanatory factors that need more research. Perceived stress and stressful life events may also have some role. Adulthood as well as childhood SES should be investigated as involved mechanisms. Finally, the sample size was not balanced, with a smaller $\mathrm{n}$ for Blacks than Whites, which has resulted in higher statistical power for Whites than Blacks. Although these limitations are present, this study is the first to test the MDRs theory ${ }^{[1,62]}$ for e-cigarette use. Including a nationally representative sample, the large sample size and use of very recent data were among the strengths of the current study.

\section{Conclusions}

In summary, the effect of educational attainment on e-cigarette use is unequal between Whites and Blacks. MDRs of educational attainment should be regarded as a deriver of tobacco inequalities by race and SES in the U.S.

\section{Acknowledgments}

Research reported in this publication was supported by the $\mathrm{NCl}$ of the National Institutes of Health and FDA Center for Tobacco Products under the award number U54CA229974. The content is solely the responsibility of the authors and does not necessarily represent the official views of the NIH or the Food and Drug Administration. Assari and Bazargan are also supported by the NIH under Award \# 54MD008149, R25 MD007610, 2U54MD007598, 
and U54 TR001627, U54 MD007598, and the CA201415-02.

\section{References}

1. Assari S. Health disparities due to diminished return among black Americans: Public policy solutions. Soc Issues Policy Rev 2018;12:112-45.

2. Assari S. Unequal gain of equal resources across racial groups. Int J Health Policy Manag 2018;7:1-9.

3. Farmer MM, Ferraro KF. Are racial disparities in health conditional on socioeconomic status? Soc Sci Med 2005;60:191-204.

4. Hudson DL, Bullard KM, Neighbors HW, Geronimus AT, Yang J, Jackson JS. Are benefits conferred with greater socioeconomic position undermined by racial discrimination among African American men? J Mens Health 2012;9:127-36.

5. Assari $\mathrm{S}$, Caldwell $\mathrm{CH}$. Family income at birth and risk of attention deficit hyperactivity disorder at age 15: Racial differences. Children (Basel) 2019;6:E10.

6. Assari S, Farokhnia M, Mistry R. Education attainment and alcohol binge drinking: Diminished returns of hispanics in Los Angeles. Behav Sci (Basel) 2019;9:E9.

7. Assari S. Family socioeconomic position at birth and school bonding at age 15; blacks' diminished returns. Behav Sci (Basel) 2019;9:E26.

8. Assari S, Mistry R. Diminished return of employment on ever smoking among hispanic whites in Los Angeles. Health Equity 2019;3:138-44.

9. Assari S. Socioeconomic determinants of systolic blood pressure; minorities diminished returns. J Health Econ Dev 2019;1:1-11.

10. Assari S. Parental education attainment and educational upward mobility; role of race and gender. Behav Sci (Basel) 2018;8:107.

11. Assari S. Socioeconomic status and self-rated oral health; diminished return among hispanic whites. Dent J (Basel) 2018;6:E11.

12. Assari S. High income protects whites but not African Americans against risk of depression. Healthcare (Basel) 2018;6:37.

13. Assari $\mathrm{S}$. The benefits of higher income in protecting against chronic medical conditions are smaller for African Americans than whites. Healthcare (Basel) 2018;6:E2.

14. Assari S. Life expectancy gain due to employment status depends on race, gender, education, and their intersections. J Racial Ethn Health Disparities 2018;5:375-86.

15. Assari S. Education attainment and obesity: Differential returns based on sexual orientation. Behav Sci (Basel) 2019;9:E16.

16. Assari S. Parental educational attainment and mental well-being of college students; diminished returns of blacks. Brain Sci 2018;8:E193.
17. Assari S. Educational attainment better protects African American women than African American men against depressive symptoms and psychological distress. Brain Sci 2018;8:E182.

18. Assari S, Mistry R. Educational attainment and smoking status in a national sample of American adults; evidence for the blacks diminished return. Int J Environ Res Public Health 2018;15:E163.

19. Assari S, Hani N. Household income and children's unmet dental care need; blacks' diminished return. Dent J (Basel) 2018;6:E17.

20. Assari $\mathrm{S}$, Caldwell $\mathrm{CH}$, Zimmerman MA. Family structure and subsequent anxiety symptoms; minorities' diminished return. Brain Sci 2018;8:E97.

21. Assari S. Perceived neighborhood safety better predicts risk of mortality for whites than blacks. J Racial Ethn Health Disparities 2017;4:937-48.

22. Assari S. General self-efficacy and mortality in the USA; racial differences. J Racial Ethn Health Disparities 2017;4:746-57.

23. Assari S, Lankarani MM. Reciprocal associations between depressive symptoms and mastery among older adults; black-white differences. Front Aging Neurosci 2016;8:279.

24. Assari S. Whites but not blacks gain life expectancy from social contacts. Behav Sci (Basel) 2017;7:E68.

25. Sawdey MD, Day HR, Coleman B, Gardner LD, Johnson SE, Limpert J, et al. Associations of risk factors of e-cigarette and cigarette use and susceptibility to use among baseline PATH study youth participants (2013-2014). Addict Behav 2019;91:51-60.

26. Barrington-Trimis JL, Bello MS, Liu F, Leventhal AM, Kong $\mathrm{G}$, Mayer $\mathrm{M}$, et al. Ethnic differences in patterns of cigarette and e-cigarette use over time among adolescents. J Adolesc Health 2019;65:359-65.

27. Pesko MF, Huang J, Johnston LD, Chaloupka FJ. E-cigarette price sensitivity among middle and highschool students: Evidence from monitoring the future. Addiction 2018;113:896-906.

28. Laverty AA, Filippidis FT, Vardavas $\mathrm{Cl}$. Patterns, trends and determinants of e-cigarette use in 28 European union member states 2014-2017. Prev Med 2018;116:13-8.

29. Springer AE, Davis C, Van Dusen D, Grayless M, Case KR, Craft $M$, et al. School socioeconomic disparities in e-cigarette susceptibility and use among central Texas middle school students. Prev Med Rep 2018;11:105-8.

30. Simon P, Camenga DR, Morean ME, Kong G, Bold KW, Cavallo DA, et al. Socioeconomic status and adolescent e-cigarette use: The mediating role of e-cigarette advertisement exposure. Prev Med 2018;112:193-8.

31. Harlow AF, Stokes A, Brooks DR. Socioeconomic and racial/ethnic differences in e-cigarette uptake among cigarette smokers: Longitudinal analysis of

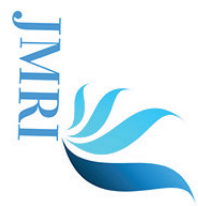


the population assessment of tobacco and health (PATH) study. Nicotine Tob Res 2019;21:1385-93.

32. Hiemstra PS, Bals R. Effects of e-cigarette use on human lung tissue. On harm reduction and causing harm. Am J Respir Crit Care Med 2018;198:6-7.

33. Ribisl KM, Seidenberg AB, Orlan EN. Comprehensive e-cigarette regulation as a step toward harm reduction. J Policy Anal Manage 2016;35:492-5.

34. Kassim S, Farsalinos KE. E-Cigarette as a harm reduction approach among tobacco smoking khat chewers: A promising bullet of multiple gains. Int J Environ Res Public Health 2016;13:240.

35. Churk SS. E-cigarette regulation and harm reduction: The case of Hong Kong. Food Drug Law J 2016;71:634-57.

36. Assari S, Moghani Lankarani M. Workplace racial composition explains high perceived discrimination of high socioeconomic status African American men. Brain Sci 2018;8:E139.

37. Assari S. Race, intergenerational social mobility and stressful life events. Behav Sci (Basel) 2018;8:E86.

38. Assari S, Caldwell $\mathrm{CH}$. Social determinants of perceived discrimination among black youth: Intersection of ethnicity and gender. Children (Basel) 2018;5:E24.

39. Assari S, Moghani Lankarani M. Poverty status and childhood asthma in white and black families: National survey of children's health. Healthcare (Basel) 2018;6:1-13.

40. Assari S, Lankarani MM. Education and alcohol consumption among older Americans; black-white differences. Front Public Health 2016;4:67.

41. Finney Rutten LJ, Blake KD, Skolnick VG, Davis T, Moser RP, Hesse BW. Data resource profile: The national cancer institute's health information national trends survey (HINTS). Int J Epidemiol 2019; 2019:dyz083.

42. Hesse BW, Greenberg AJ, Peterson EB, Chou WS. The health information national trends survey (HINTS): A resource for consumer engagement and health communication research. Stud Health Technol Inform 2017; 240:330-46.

43. Nelson DE, Kreps GL, Hesse BW, Croyle RT, Willis G, Arora NK, et al. The health information national trends survey (HINTS): Development, design, and dissemination. J Health Commun 2004;9:443-60.

44. Ramo DE, Hall SM, Prochaska JJ. Reliability and validity of self-reported smoking in an anonymous online survey with young adults. Health Psychol 2011;30:693-701.

45. Wong DN, Fan W. Ethnic and sex differences in E-cigarette use and relation to alcohol use in California adolescents: The California health interview survey. Public Health 2018;157:147-52.

46. Assari S. Family income reduces risk of obesity for white but not black children. Children (Basel)
2018;5:E37.

47. Assari S, Thomas A, Caldwell CH, Mincy RB. Blacks' diminished health return of family structure and socioeconomic status; 15 Years of follow-up of a national urban sample of youth. J Urban Health 2018;95:21-35.

48. Assari S. Blacks' diminished return of education attainment on subjective health; mediating effect of income. Brain Sci 2018;8:E176.

49. Assari S, Lapeyrouse LM, Neighbors HW. Income and self-rated mental health: Diminished returns for high income black Americans. Behav Sci (Basel) 2018;8:E50.

50. Assari S, Preiser B, Kelly M. Education and income predict future emotional well-being of whites but not blacks: A ten-year cohort. Brain Sci 2018;8:E122.

51. Assari S, Caldwell CH, Mincy R. Family socioeconomic status at birth and youth impulsivity at age 15; blacks' diminished return. Children (Basel) 2018;5:E58.

52. Assari S. Parental education better helps white than black families escape poverty: National survey of children's health. Economies 2018;6:30.

53. Daly MC, Duncan GJ, McDonough P, Williams DR. Optimal indicators of socioeconomic status for health research. Am J Public Health 2002;92:1151-7.

54. The national health interview survey design, 1973-84, and procedures, 1975-83. Vital Health Stat 1 1985;18:1-27.

55. Assari S, Caldwell CH, Mincy RB. Maternal educational attainment at birth promotes future selfrated health of white but not black youth: A 15-year cohort of a national sample. J Clin Med 2018;7:93.

56. Assari S. Parental educational attainment and academic performance of American college students; blacks' diminished returns. J Health Econ Dev 2019;1:21-31.

57. Navarro V. Race or class or race and class: Growing mortality differentials in the United States. Int J Health Serv 1991;21:229-35.

58. Navarro V. Race or class versus race and class: Mortality differentials in the United states. Lancet 1990;336:1238-40.

59. Navarro V. Race or class, or race and class. Int J Health Serv 1989;19:311-4.

60. Wagner KJP, Bastos JL, Navarro A, Gonzalez-Chica DA, Boing AF. Socioeconomic status in childhood and obesity in adults: A population-based study. Rev Saude Publica 2018;52:15.

61. Gee GC, Hing A, Mohammed S, Tabor DC, Williams DR. Racism and the life course: Taking time seriously. Am J Public Health 2019;109:S43-7.

62. Williams AJ, Lai $Z$, Knight $S$, Kamali $M$, Assari S, Mclnnis MG. Risk factors associated with antidepressant exposure and history of antidepressant-induced mania in bipolar disorder. J Clin Psychiatry 2018;79:17m11765. 